\title{
The short life of a terminal care support team: experience at Charing Cross Hospital
}

\author{
ANDREW HERXHEIMER, RICHARD BEGENT, DORRIE MACLEAN, LYN PHILLIPS, \\ BARBARA SOUTHCOTT, IVAN WALTON
}

The introduction and success of the hospice movement in Great Britain and, notably, the pioneering work of Dame Cicely Saunders established a new standard for the care of dying patients. It has, however, been generally recognised that only a few dying patients can ever be looked after in hospices. ' Several hospital based teams have therefore come into being with the aim of improving the control of symptoms and providing spiritual and practical support for both patients and their relatives in the more general situation of a hospital and its district.

In 1980 a proposal by two of us to start a hospital based terminal care support team was put to the consultants in the medical and surgical divisions and the medical executive committee at Charing Cross Hospital. After full discussion it was accepted, and in 1982 the then district management team agreed to the appointment of a full time nurse to act as a nucleus for the team. In March 1982 a nursing sister was appointed together with six volunteers-five doctors (a radiotherapist, two medical oncologists, a geriatrician, and a clinical pharmacologist, all with experience of terminal care) and the hospital chaplain. Later a part time volunteer secretary joined the team, and from November 1982 a full time social worker was

\footnotetext{
Charing Cross Hospital and Charing Cross and Westminster Medical School, London W6 8RF

ANDREW HERXHEIMER, FRCP, senior lecturer in clinical pharmacology and therapeutics

RICHARD BEGENT, MD, MRCP, senior lecturer, department of medical oncology

DORRIE MACLEAN, BA, CQSW, medical social worker

LYN PHILLIPS, BA, hospital chaplain

BARBARA SOUTHCOTT, DMRT, FRCP, senior lecturer, departments of surgery and radiotherapy

IVAN WALTON, MSC, MRCP, physician in geriatrics

Correspondence to: Dr A Herxheimer.
}

attached half time to the group and a health visitor gave two sessions a week. As a result of cuts in the district budget the funding for the only full time post was withdrawn on 31 December 1983 and the terminal care team was disbanded.

This paper analyses not so much the team's achievements but the problems it encountered, the possible flaws in its structure, and the shortcomings in financial support that contributed to its demise at this time of increased interest and enthusiasm for such hospital teams.

\section{Role of the team}

At the outset all the medical staff and major committees were informed of the existence of the team. We saw its role as being fourfold. It could provide: (a) practical help in the management of the dying patient and the control of symptoms by providing a 24 hour on call service for both hospital staff and the district, $(b)$ a support and counselling service for patients, relatives, and occasionally ward staff, $(c)$ coordination of hospital and district services for the dying patient to aid the smooth transfer of patients from one sector to another, and (d) help in training junior staff, medical students, and nurses in the care of the dying, which is important in a teaching hospital.

The composition of the team reflected these aims. Most of the members were likely, in their other everyday duties, to have had considerable experience with terminally ill patients and some particular skills that would widen the collective expertise of the team. We were aware that, in the context of both hospital and district, such a team could be seen as attempting a takeover of patients in other consultants' beds, with implied criticism of their management, or at least as constituting an unwarranted and time wasting interference. The initial proposal emphasised the purely advisory role of the team (which had no beds) and the fact that it was offering help and support, not alternative management. 


\section{How the team worked}

The doctors focused mainly on controlling symptoms, and the social worker and chaplain on the psychosocial and spiritual aspects, while the nurse coordinated and took part in all these functions. The team's work consisted of giving, firstly, advice to professionals, from any member of the team, and, secondly, direct careparticularly of a psychosocial, emotional, and spiritual nature, including bereavement support-to patients and their families, alongside and in cooperation with the hospital and community staff.

A patient was referred to the team by or with the approval of the consultant or general practitioner in charge. A team member, usually the nursing sister, then saw the patient and discussed the patient's care and problems with the referring person and with the team. After this joint assessment the most relevant member of the terminal care support team was identified-usually the sister or the social worker-and a plan of action offered to the referring team. Giving direct care entailed offering extra support to the patient and his family in the community. This included a 24 hour on call service providing mainly advice and, on occasions, direct help. Ready access to help and advice at night and weekends is essential for patients dying at home when there is no regular district nursing cover and especially when many general practices are covered by a deputising service at these times.

Although the purpose of the team is clear and simple to describe on paper, in practice it was beset by several persistent problems. Some of these were due to the amorphous format of the team and the almost impossible burden that this placed on its only full time member, some due to mistrust of the team and even direct opposition from staff within both the hospital and the district, and some simply because terminal illness is difficult to manage and is a severe test of medical, nursing, and social skills.

\section{What went wrong?}

The loss of our one full time member was primarily the result of financial and manpower restrictions. It is pertinent, however, to examine critically the 18 months of the team's existence. The team was formed within the hospital and had to function within the existing framework of care. This necessarily led to a rather different set of problems from, for example, a hospice that is purpose built for terminal illness, not only architecturally but also medically and socially. There were seven main areas of difficulty.

\section{LACK OF A DESIGNATED LEADER}

None of the doctors had regular sessions allocated to the team but gave time in addition to their usual work. In most teams and hospices a doctor is an identifiable figurehead who provides a focus and a vision of the team's boundaries and possibilities. Doctors more easily accept advice from a doctor than from a nurse and prefer to refer patients to a doctor; a doctor can relate authoritatively to both hospital and community nursing hierarchies and to medical peers. Furthermore, a doctor can provide a coherent programme of education for all levels of professional staff in the hospital-nurses, medical students, doctors, social workers, and others.

\section{INTERNAL DIFFICULTIES}

It took time for the team to recognise and use the different roles and skills of its individual members. For the volunteer members other commitments greatly limited the time available for team work and resulted in a lack of continuity and cohesion. In retrospect the medical staff should have had a more disciplined involvement, with on call rotas. The dual role of the medical staff caused some uncertainty with referring teams, who clearly thought that sometimes the medical staff brought a "departmental" rather than a "terminal care team" approach to a problem. The social worker also had a dual role since half her time was allocated elsewhere. For all these reasons referring staff tended to identify the team mainly in terms of the nursing sister. These problems were clarified and to some extent eased by the team regularly discussing its methods of functioning with two senior staff members of the Cassel Hospital, who acted as consultants.

\section{STAFFING}

In retrospect the team clearly had far too few paid members. When the team was formed there was a struggle to achieve the appointment of just one nursing sister, who was concerned in all the patient referrals, domiciliary visits, education, and often secretarial work. The enormous workload was not foreseen, and it placed an almost impossible burden on one person. All the other members of the team except the part time social worker and health visitor were volunteers with full time commitments elsewhere. This made them less accessible to the nursing sister and compounded difficulties with her own workload.

A comparison with teams elsewhere illustrates this understaffing. At University College Hospital the paid staff consists of a clinical assistant (five sessions a week), two full time nursing sisters, a full time social worker, and a full time secretary. At St Thomas's Hospital it includes a full time doctor working in the hospital and community, one full time senior nurse in the hospital, three full time nurses in the community, a full time nurse/bereavement counsellor, a full time secretary, and a social worker employed part time. ${ }^{2}$ We could not expect to start off as a large team, but in retrospect the resources allowed were impossibly meagre.

\section{LACK OF A TEAM BASE}

Team members' offices were in different parts of the hospital. A team office would have helped communication, with information being shared as it came in, provided a geographical focus for patients and relatives, being a place where they could find the team and where they could be welcomed, and increased the opportunities for mutual support, which team members need to give one another.

\section{REFERRALS}

In retrospect the system for referrals was less clear than it should have been, and some misunderstandings and difficulties arose, especially when several teams were involved. Some consultants felt strongly that if a patient was referred to them they had to take responsibility for terminal care themselves.

\section{COMMUNICATION}

Ironically, though improved communications (hospital to district and vice versa) were a particular aim of the team, its own loose structure and the fact that the team members worked in different parts of the hospital led to poor communication internally, which at times impeded the flow of information to all parties concerned with a particular patient.

\section{FUNDING}

A year after the team was set up the Hammersmith and Fulham District Health Authority entered a phase of severe financial constraint and budgetary review. Scrutiny indicated that the salary for the nursing sister had not been properly budgeted for. The post was therefore subjected to critical review at a time when the team was already planning to appoint a second full time sister, using funds from a cancer charity. The review unfortunately resulted in the loss of the one post that was central to the team's work. 


\section{Discussion}

Although there were serious problems with the structure of the team and its internal and external functioning, much was achieved during its 18 month existence. A total of 130 cases were referred to the team. The reasons for referral varied from simple on the spot advice or passing on of an appropriate address or telephone number to seeing the patient and his relatives regularly for weeks or months, carrying out domiciliary visits, and attending meetings with all the other professional persons concerned. Regular lectures were given to the nursing staff and several postgraduate meetings were held in the hospital, particularly for the local general practitioners and district nurses. A particular effort was made at these meetings to underline the supportive and assisting role of the team, but it soon became clear that some people opposed the concept of the team. This ranged from a general feeling that the team was a collection of "busybody do-gooders" to a rather more specific complaint that the team was interfering with management and attempting to take over the care of the patient; the presence of the team was seen as threatening. The team was bitterly criticised for problems that were thought to be due to its failings, whereas the team sometimes considered that they were being blamed for mistakes that were not necessarily their own.

The demise of the team may or may not be seen as a failure. All of us who worked in the team learnt much that we value and will use in future work. We believe that other members of the staff learnt with us. Our brief existence as a team caused others to look at their management of the dying patient, and that was important. We are convinced that staff in hospitals do need more resources to help them cope with the dying. There is no simple formula that can be used since hospitals, their districts, and their resources vary. What is appropriate in one hospital may fail in another.

\section{Subsequent developments}

After the team was disbanded the district health authority convened a working party to recommend future policy on terminal care. The working party, which included three members of the disbanded team, concluded that it would be inappropriate to appoint a consultant for terminal care because this function was already the responsibility of the four consultants in medical oncology and the three in radiotherapy as well as of several other specialised physicians and surgeons. Its report (available from the District Medical Officer, Riverside Health Authority, 116 Fulham Palace Road, London W6 8RF), which has now been accepted, recommends $(a)$ the establishment of a health care planning team for the terminally ill that will organise and evaluate education and advice on terminal care for the medical and nursing staff in the whole district; $(b)$ the appointment of two MacMillan nurses and a secretary; and $(c)$ a continuous audit of the management of terminal care in the district with a view to improving the quality of terminal care within the framework of the existing medical and social services. These proposals will be implemented when funds have been found.

\section{Recommendations}

Our experience indicates, firstly, that a team approach requires sound leadership, which in a hospital setting must come from an experienced and trusted clinician. A specific doctor and perhaps a deputy should be identified and recognised as offering help with terminal care. This doctor would have the services of specialist hospice trained nurses to follow through treatment recommendations and to facilitate psychosocial support. Secondly, funding must be provided for a viable nucleus of staff; we believe this should consist of a minimum of one part time doctor, a full time social worker, two full time nurses, and a part time secretary. Thirdly, good communications at every level are crucial to the smooth functioning of a team.

In some hospitals where a doctor is not appropriate, as at Charing Cross, or is not available an alternative may be to set up an education and advice service using existing specialties supplemented by hospice trained nurses to work within the nursing service. The relation of the nurses to the medical staff would thus be indirect. Their main role would be to heighten general awareness of the needs for and problems with terminal care in the district rather than to play a direct part in care. Requests for medical advice, for example with pain control, would be made in the usual way by one consultant to another. Such a service requires a minimum of two full time nurses with secretarial support and a staff committee to organise education and audit.

It is all too easy to talk about the care of the dying patient and yet do nothing positive to try to improve management. We believe that every district could benefit from thoughtful planning of terminal care, whichever model is followed. There is no doubt that many patients now die in hospitals and at home peacefully and with dignity, being cared for with skill and compassion. It is no slur on the hard work and dedication that already exist to suggest that there is room for improvement.

We thank other members of the team, particularly Sister Lucy Stewart, whose contribution was central to the team, for their enthusiasm and hard work and our many colleagues in the hospital and the community for their cooperation.

\section{References}

1 Department of Health and Social Security Report of working group on terminal care. London DHSS, 1980.

2 Bates T, Hoy AM, Clarke DG, Laird PP. The St Thomas' Hospital terminal care support teamnew concept of hospice care. Lancet $1981 ;$ i: 1201-3.

Accepled 12 March 1985

\section{MATERIA NON MEDICA}

\section{The blackbird and the Fortresses}

Sheltering from the chill wind in my garden I listened with admiration to the melodious voice of a solitary blackbird. He sang determinedly withou pause, as if to celebrate his survival of an exceptionally hard winter, and as a jetload of tourists rumbled upwards towards some more welcoming costa he seemed to redouble his efforts in response. In that moment my mind leap back exactly 40 years. It was 24 March 1945, spring had come early, and I lay in a warm sun by the river on the backs of St John's College, Cambridge, relaxed and mentally drained at the end of an entrance scholarship examination. Some servicemen were larking about in punts. The streets were jammed solid by huge trucks of the US Air Force. Italian prisoners roamed the pavements and sat on the bridges, and a column of tanks was resting on Queen's Road. From overhead came a continuous all pervading hum and drone, swelling to drum rolls, fading to murmurations, and between the soft clouds glinted shoal upon shoal of Flying Fortresses and Liberators, massed in unbelievable numbers that seemed to multiply the harder one looked. And in the willow tree beside me a blackbird was singing.

Suddenly a monstrous reverberation filled the whole world and a huge armada swept in at low level from the east, close packed in ragged lines, stacked closely on each other so that wings and tails seemed to interlock. I vividly recall a straggler in the rear, roaring straight over King's chapel, its tall tail a skeleton, two Fortresses above and behind like sheepdogs. A final blast echoed back from St John's New Court and everything was still. It was hard to believe that the gentle sky had just held such a tonnage of metal, that loose skeins of thousands of men were still suspended over the fenlands. Astonishingly, in a quiet pause the unbowed blackbird's voice came again, singing his heart out under some mysterious and timeless compulsion in the Easter sunshine.

As we soon learnt, that morning the Allied armies had crossed the Rhine, backed by the second greatest aerial assault in history. In one sense that day could be seen as a pinnacle of human endeavour, ingenuity, and courage; but the blackbird made it all seem such a monumental irrelevance-an aberration once more afflicting nature's most unstable and destructive species.-R D MONTGOMERY, consultant physician, Birmingham. 